\title{
Effect of Elevated Temperatures on Lateral Earth Pressures in Unsaturated Soils
}

\author{
Sannith Kumar Thota ${ }^{1}$ and Farshid Vahedifard ${ }^{1, *}$ \\ ${ }^{1}$ Department of Civil and Environmental Engineering, Mississippi State University, MS, USA
}

\begin{abstract}
Near-surface unsaturated soils can be exposed to elevated temperatures due to soil-atmospheric interactions under drought events, wildfires, heatwaves, and warm spells, or the heat induced by emerging geotechnical and geo-environmental technologies such as geothermal boreholes and thermally active earthen systems. Elevated temperatures can affect the hydro-mechanical characteristics of unsaturated soils, which in turn can alter lateral earth pressures developed in the backfill soil. The main objective of this study is to quantify the effect of elevated temperatures on active and passive earth pressures of unsaturated soils. For this purpose, the paper presents the derivation of an analytical framework to extend Rankine's earth pressure theory to account for the effect of temperature under hydrostatic conditions. The equations are derived by incorporating the effect of temperature into the soil water retention curve and a suction stress-based effective stress representation. The proposed effective stress equation considers the temperature-induced changes in the contact angle, surface tension, and enthalpy of immersion. To investigate the impact of temperature on active and passive earth pressures, the proposed method is then used in a set of parametric studies to determine active and passive earth pressure profiles for three hypothetical soils of clay, silt, and sand at different temperatures. Results suggest that elevated temperatures can cause variation in active and passive earth pressures for all the soils considered. The findings of this study can contribute toward analyzing earth retaining structures subjected to elevated temperatures.
\end{abstract}

\section{Introduction}

Earth retention systems such as retaining walls and MSE walls are primarily designed and analyzed using lateral earth pressure methods. Backfill soils in these systems are mostly in an unsaturated state during the life span of the structure, which highlights the importance of considering unsaturated soil mechanics for lateral earth pressure calculations. To address this need, several studies have extended classical earth pressure theories such as Rankine's and Coulomb's methods to unsaturated soils to account for the role of matric suction [1-3]. For example, $\mathrm{Lu}$ and Likos [2] extended Rankine's method by incorporating a suction stress-based effective stress representation. Liang et al. (4) extended Coulomb's method to unsaturated soils using two independent stress state variables. Vahedifard et al. [3] presented an analytical framework for calculating the thrust of active earth pressures under unsaturated steady flow conditions by employing the suction stress-based effective stress and a log spiral surface. Shahrokhabadi et al. [5] incorporated the effect of transient unsaturated seepage into Rankine's theory.
All of the existing models for determining lateral earth pressures in unsaturated soils are developed and applicable only under ambient temperature. However, unsaturated backfill soils can be exposed to elevated temperatures due to soil-atmospheric interactions under drought events, wildfires, heatwaves, and warm spells, or the heat induced by emerging geotechnical and geo-environmental technologies such as geothermal boreholes and thermally active earthen systems [6-8]. Some of the thermal energy applications require maintaining at least $35^{\circ} \mathrm{C}$ to operate the system [8]. The soil surrounding the solid waste landfills in vertical trenches may undergo temperatures as high as $50-80{ }^{\circ} \mathrm{C}$ depending on the nature of decomposition [9]. Further, it is reported that earth retention systems are frequently subjected to elevated temperatures of over $50{ }^{\circ} \mathrm{C}$ in arid environments, which can considerably increase the temperature within the backfill soil as well [10].

Temperature can have a notable impact on hydromechanical response of unsaturated soils [11-13], and thus on lateral earth pressures. Elevated temperatures can affect matric suction and degree of saturation, which are the critical parameters controlling the suction stress and,

\footnotetext{
Corresponding author: farshid@ cee.msstate.edu
} 
subsequently, the hydro-mechanical behavior of unsaturated slopes and earthen structures [11-13]. Therefore, it is prudent to consider the effects of temperatures in lateral earth pressure calculations for applications involving elevated temperatures. However, there is no theoretical model in the current literature to estimate earth pressure under elevated temperatures.

The current study aims to develop closed-form models to calculate active and passive earth pressures for unsaturated soils under elevated temperatures. A temperature-dependent model for the suction stress-based effective stress recently developed by Vahedifard et al. [13-14] is used, which incorporates two primary temperature-dependent variables of matric suction and effective degree of saturation. The temperature-dependent effective stress is then incorporated into Rankine's classic earth theory to extend it to unsaturated soils subjected to elevated temperature. The proposed models are exercised for three hypothetical soil types of clay, silt, and sand to determine active and passive earth pressure profiles under hydrostatic conditions at surface temperatures of 25,40 , and $55^{\circ} \mathrm{C}$.

\section{Theory and Formulations}

\subsection{Effective stress in unsaturated soils}

Building upon Bishop's effective stress theory [15], the suction stress-based effective stress is used in this study to describe the state of stress in unsaturated soils as follows $[2,16]$ :

$$
\sigma^{\prime}=\sigma-u_{a}-\sigma^{s}
$$

where $\sigma^{\prime}$ is effective stress, $\sigma$ is the total stress, $u_{a}$ is the pore-air pressure (which is assumed to be equal to the atmospheric pressure in this study), and $\sigma^{s}$ is the suction stress, which can be calculated as [16]:

$$
\sigma^{s}=-\psi S_{e}
$$

where $\psi$ is the matric suction, representing the difference between pore-air pressure and pore-water pressure, and $S_{e}$ is the effective degree of saturation and can be represented by a soil-water retention curve (SWRC) model [16-17].

\subsection{Temperature-dependent suction stress profile versus depth under hydrostatic condition}

To establish a relationship between the matric suction and the degree of saturation, we use the Brooks and Corey SWRC model [18] (referred to as the BC model hereafter), recently extended to temperature-dependent conditions by Vahedifard et al. [13-14]. The extended BC SWRC model considers the effect of temperature on capillarity as a function of surface tension, contact angle, and enthalpy of immersion per unit area for unsaturated soils. These formulations further are used to develop expressions for matric suction, effective degree of saturation and suction stress under elevated temperatures.

The matric suction depth profile generally varies depending on the soil type, effective degree of saturation, and the depth of the water table. Using Darcy's law, one can express the matric suction in terms of depth and hydraulic parameters [19]. A one-dimensional matric suction profile under hydrostatic conditions as a temperature-dependent quantity is expressed as [12-15]:

$$
\psi=\gamma_{w} z\left(\frac{\beta_{T_{r}}+T_{r}}{\beta+T}\right)
$$

where $\beta_{T r}$ and $\beta$ are regression parameters depending on the contact angle and enthalpy of immersion, and $T$ is the temperature in Kelvin, $T_{r}$ is the reference temperature, $\gamma_{w}$ is the unit weight of water, and $z$ is the depth above the water table. Fig. 1 shows the variation of matric suction with depth at various temperatures. For all soils, it is evident that the matric suction increases with an increase in temperature.

Using Gardner's hydraulic function, the BC SWRC model and Eq. 3, the temperature-dependent effective saturation depth profile under hydrostatic conditions can be written as:

$$
S_{e}=\left\{\exp \left[-\beta^{\prime} z\left(\frac{\beta_{T_{r}}+T_{r}}{\beta+T}\right)\right]\right\}^{1 / n}
$$

where $\beta^{\prime}$ and $n$ are the SWRC fitting parameters related to air entry pressure and the pore size distribution, respectively. By incorporating Eqs. 3 and 4 into Eq. 2, the final expression for temperature-dependent suction stress versus depth under hydrostatic condition is:

$$
\sigma^{s}=\left\{\exp \left[-\beta^{\prime} z\left(\frac{\beta_{T_{r}}+T_{r}}{\beta+T}\right)\right]\right\}^{1 / n} \gamma_{w} z\left(\frac{\beta_{T_{r}}+T_{r}}{\beta+T}\right)
$$



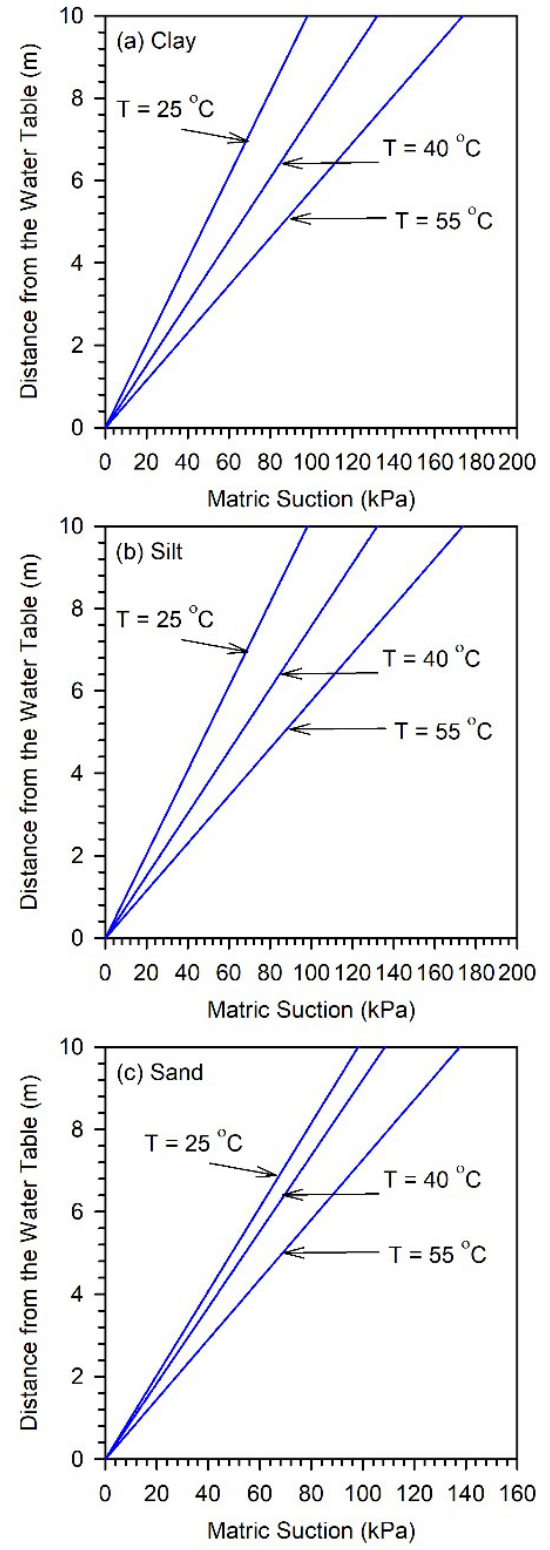

Fig. 1. Depth profiles of matric suction: (a) clay (b) silt and (c) sand soils at temperatures 25,40 , and $55^{\circ} \mathrm{C}$.

\subsection{Lateral earth pressures of unsaturated soils at elevated temperatures}

We use Eqs. 3-5 to extend Rankine's active and passive earth pressure formulations for unsaturated soils proposed by $\mathrm{Lu}$ and Likos [4] to temperature-dependent conditions. Fig. 2 depicts the schematic diagram of active and passive earth pressures for unsaturated soils under elevated temperatures. A steady temperature is applied on the soil surface and is assumed to remain constant throughout the depth. The temperature-dependent active and passive earth pressure profiles versus depth for unsaturated soils are determined as:

$$
\begin{aligned}
& \sigma_{h}-u_{a}=\left(\sigma_{v}-u_{a}\right) K_{a}-2 c^{\prime} \sqrt{K_{a}} \\
& -\left\{\exp \left[-\beta^{\prime} z\left(\frac{\beta_{T_{r}}+T_{r}}{\beta+T}\right)\right]\right\}^{1 / n} \gamma_{w} z\left(\frac{\beta_{T_{r}}+T_{r}}{\beta+T}\right)\left(1-K_{a}\right) \\
& \sigma_{h}-u_{a}=\left(\sigma_{v}-u_{a}\right) K_{p}+2 c^{\prime} \sqrt{K_{p}} \\
& -\left\{\exp \left[-\beta^{\prime} z\left(\frac{\beta_{T_{r}}+T_{r}}{\beta+T}\right)\right]\right\}^{1 / n} \gamma_{w} z\left(\frac{\beta_{T_{r}}+T_{r}}{\beta+T}\right)\left(1-K_{p}\right)
\end{aligned}
$$

where $\sigma_{h}$ is the horizontal earth pressure, $\sigma_{v}=\left(T^{\prime}-z\right) \gamma$ is the vertical earth pressure can also be termed as the overburden pressure, $T^{\prime}$ is the total depth of overburden, which can vary as $\mathrm{T}_{\mathrm{a}}$ or $\mathrm{T}_{\mathrm{p}}$ depending on active or passive mode, $\gamma$ is the unit weight of soil, $c^{\prime}$ is the cohesion, $K_{a}$ is the coefficient of active earth pressure, $K_{p}$ is the coefficient of passive earth pressure.

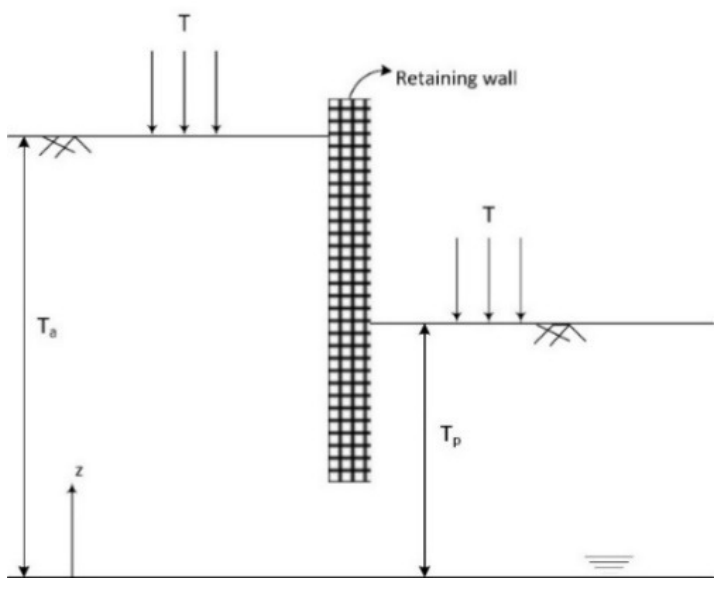

Fig. 2. Schematic diagram of active and passive earth pressures for unsaturated soils under elevated temperatures.

The right side of the retaining wall in Fig. 2 represents the passive mode of lateral earth pressure where the soil is in a compressive state. The water table is set $6 \mathrm{~m}$ below the surface on this side. In the passive region, the horizontal pressure increases and is greater than the vertical pressure. The left side of the wall is in the active state of lateral earth pressure where the wall moves away from the soil. The water table is set at $10 \mathrm{~m}$ from the fill surface on this side. The horizontal pressure reduces and is less than the vertical pressure in the active region. Therefore, depending on the region considered, the overburden pressure changes.

\section{Results and Discussion}

The depth profiles for active and passive earth pressures at different suction stress under hydrostatic conditions can be calculated by Eqs. 6 and 7, respectively. The hydraulic and 
shear strength parameters for the soil types used in the analysis are shown in Table 1.

Table 1. Input parameters used for earth pressure calculations.

\begin{tabular}{|c|c|c|c|c|c|c|}
\hline \multirow{2}{*}{ Soil } & \multicolumn{3}{|c|}{$\begin{array}{c}\text { Hydraulic } \\
\text { parameters }\end{array}$} & \multicolumn{2}{c|}{$\begin{array}{c}\text { Shear } \\
\text { strength } \\
\text { parameters }\end{array}$} & \multirow{2}{*}{ Geometry } \\
\cline { 2 - 5 } & $n$ & $\begin{array}{c}\beta^{\prime} \\
\left(\mathrm{kPa}^{-1}\right)\end{array}$ & $\begin{array}{c}\Delta h_{T_{r}} \\
\left(\mathrm{~J} / \mathrm{m}^{2}\right)\end{array}$ & $\phi^{\prime}$ & $\begin{array}{c}c^{\prime} \\
(\mathrm{kPa})\end{array}$ & \multirow{2}{*}{$\begin{array}{c}\mathrm{T}_{\mathrm{a}}=10 \mathrm{~m} \\
\mathrm{~T}_{\mathrm{p}}=6 \mathrm{~m}\end{array}$} \\
\cline { 1 - 5 } Clay & 2 & 33.33 & -0.516 & $25^{\circ}$ & 10 & \\
\cline { 1 - 5 } Silt & 3 & 3.33 & & $33^{\circ}$ & 2 & \\
\cline { 1 - 5 } Sand & 4 & 3 & -0.285 & $35^{\circ}$ & 0 & \\
\hline
\end{tabular}

Fig. 3 shows the depth profiles for the clay at temperatures 25,40 , and $55{ }^{\circ} \mathrm{C}$, respectively. The results plotted to show the effect of temperature on suction stress, active and passive pressures at various depths. The absolute magnitude of suction stress decreases with an increase in temperature from ambient conditions. For instance, when the temperature increases from $25^{\circ} \mathrm{C}$ to 40 ${ }^{\circ} \mathrm{C}$ and $55{ }^{\circ} \mathrm{C}$ at a depth $4 \mathrm{~m}$ above the water table, the suction stress decreases by $31 \%$ and $68 \%$, respectively (Fig. 3a). Changes in the degree of saturation could affect matric suction in unsaturated soils. These could further affect suction stress of the soil under elevated temperatures. The changes in matric suction with temperature are attributed to temperature-induced changes in the surface tension, contact angle and wettability of soil [12-14].

At elevated temperatures, the increase in suction stress decreases the active earth pressure and increases the passive pressure as shown in Figs. 3(b) and 3(c), respectively. Consistent with temperature-induced changes in the suction stress, the active earth pressure decreases by $75 \%$ and $150 \%$ and the passive earth pressure increases by $9 \%$ and $21 \%$ by raising the temperature from 25 to $55^{\circ} \mathrm{C}$. It is observed that the tension zone (i.e., negative earth pressure) varies depending on temperature and depth. The zone of soil layer under tension stress increases with an increase in temperature. The top layers of $5 \mathrm{~m}$ for $25^{\circ} \mathrm{C}$, $5.5 \mathrm{~m}$ for $40{ }^{\circ} \mathrm{C}$, and $6 \mathrm{~m}$ for $55{ }^{\circ} \mathrm{C}$ are under negative active earth pressures, respectively. The increase in the tension zone may cause cracks to propagate deeper from the surface. The formation of deeper tension cracks followed by variation in the degree of saturation may cause drastic pore-water pressure changes in the soil. The changes in the properties with temperature are attributed to the physicochemical variation of pore-water on and around the soil particles, which can have a notable effect on lateral earth pressures and cracked zone.
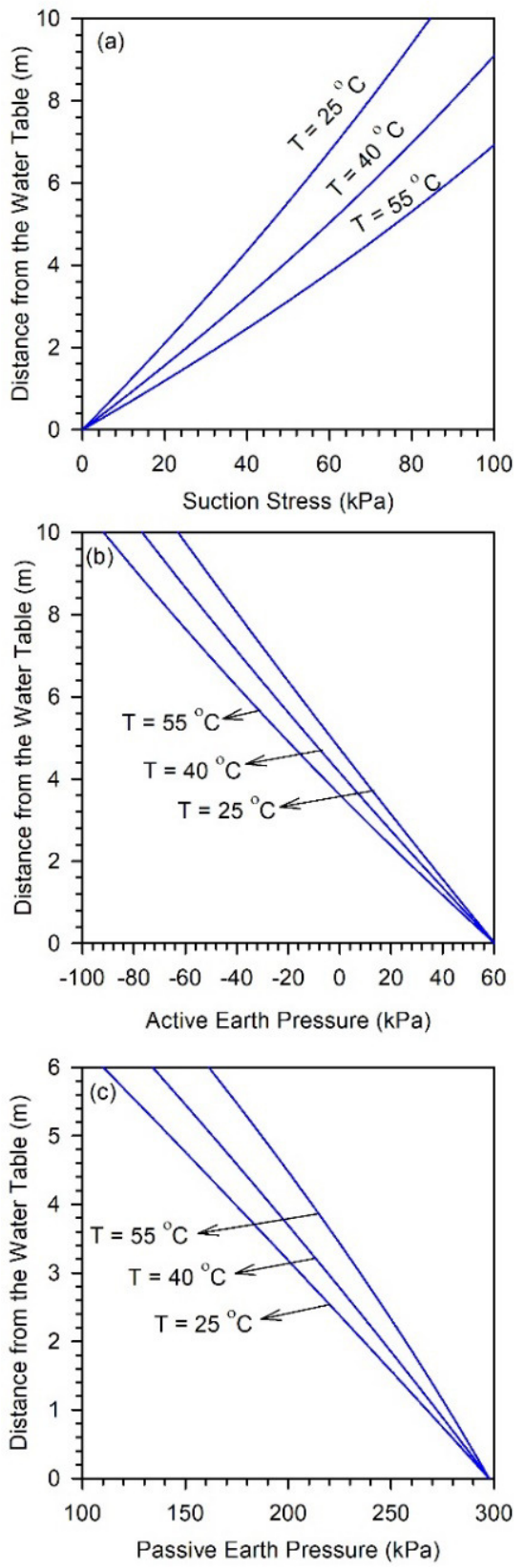

Fig. 3. Depth profiles of (a) suction stress (b) active earth pressure and (c) passive earth pressure for clayey soil at temperatures 25,40 , and $55^{\circ} \mathrm{C}$.

Fig. 4 shows the depth profiles of the silty soil at temperatures of 25,40 , and $55{ }^{\circ} \mathrm{C}$, respectively. A similar trend is observed for the silt with a relative change in each property is lesser than observed for the clay. At depth $4 \mathrm{~m}$ above the water table, the suction stress increases by $20 \%$ and $37 \%$ (Fig. 4a). The active earth pressure (Fig. 4b) decreases by $24 \%$ and $46 \%$ and the passive earth pressure (Fig. 4c) increases by $5 \%$ and $10 \%$ with the elevation of temperature from $25{ }^{\circ} \mathrm{C}$ to $40{ }^{\circ} \mathrm{C}$ and $55^{\circ} \mathrm{C}$, respectively. 

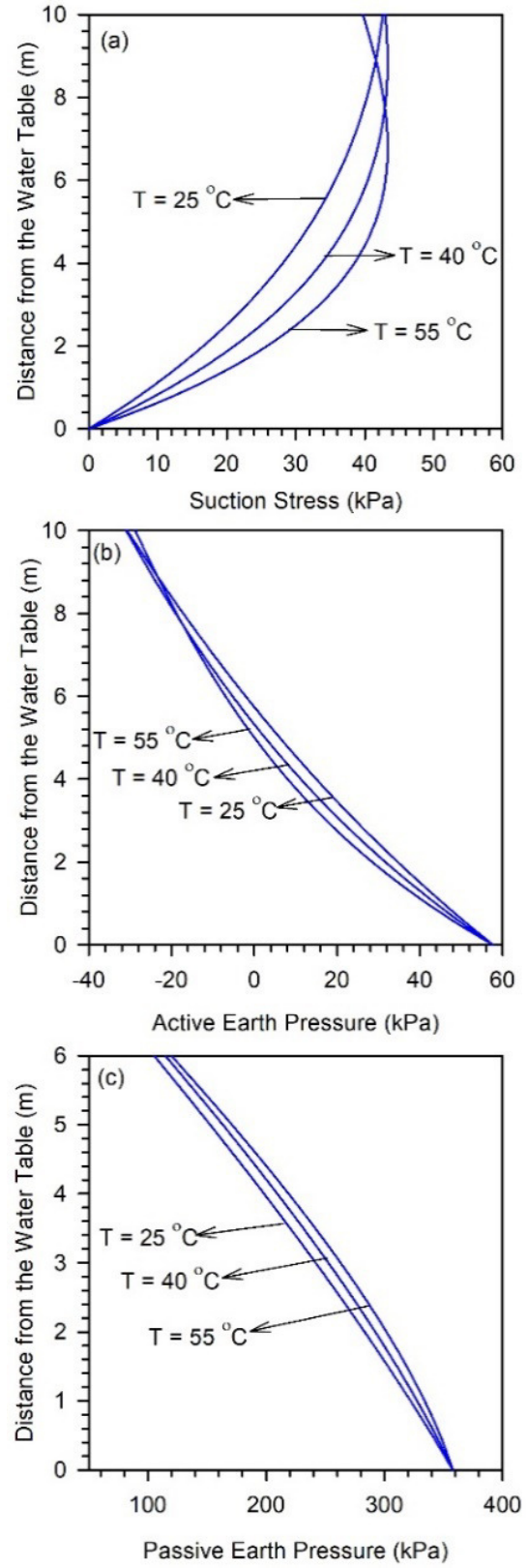

Fig. 4. Depth profiles of (a) suction stress (b) active earth pressure and (c) passive earth pressure for silty soil at temperatures 25,40 , and $55^{\circ} \mathrm{C}$.

Fig. 5 shows the depth profiles of the sandy soil at temperatures of $25{ }^{\circ} \mathrm{C}, 40{ }^{\circ} \mathrm{C}$, and $55^{\circ} \mathrm{C}$, respectively. The plots indicate the hydrostatic condition has minimal effect on suction stress and thus insignificant contribution to changes in active and passive earth pressures. However, the elevation of temperature from ambient conditions can have a relatively noticeable effect on suction stresses profiles and hence, on the lateral earth pressures. For instance, at a distance of $4 \mathrm{~m}$ above the water table and if the temperature increases from 25 to 40 and $55^{\circ} \mathrm{C}$, the suction stress (Fig. 5a) increases approximately by $6 \%$ and $22 \%$ and the active earth pressure (Fig. 5b) decreases by $9 \%$ and $32 \%$ and the passive earth pressure (Fig. 5c) increases by $2 \%$ and $7 \%$, respectively.
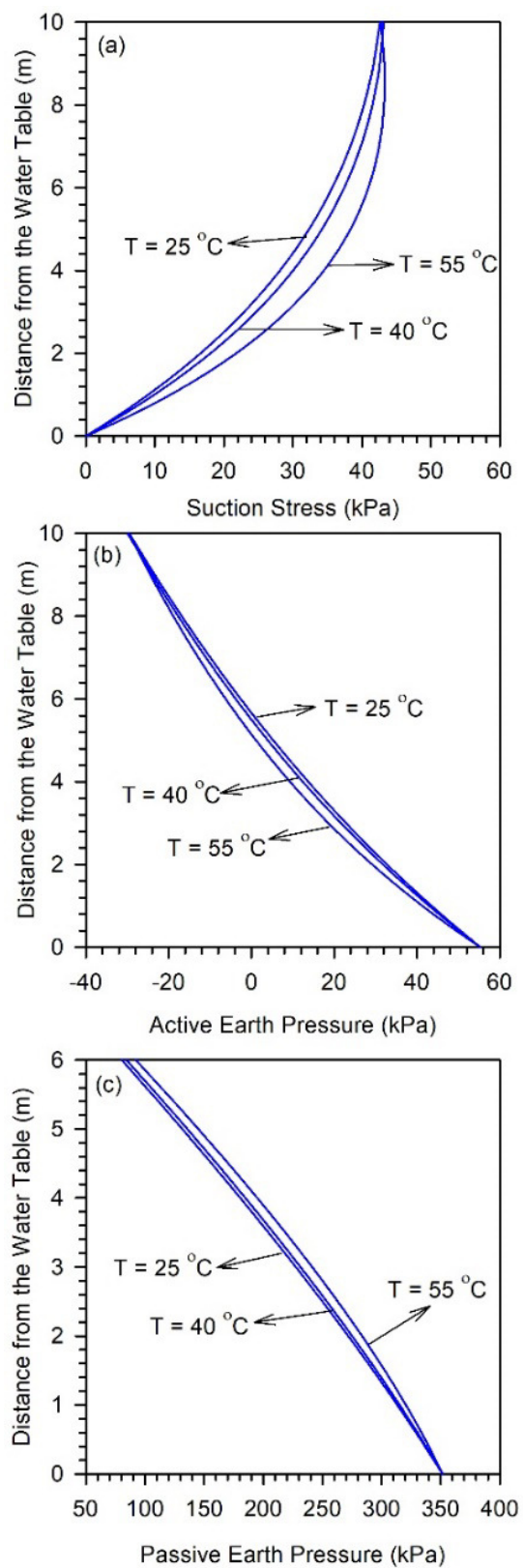

Fig. 5. Depth profiles of (a) suction stress (b) active earth pressure and (c) passive earth pressure for sandy soil at temperatures 25,40 , and $55^{\circ} \mathrm{C}$.

\section{Conclusions}

In this paper, Rankine's earth pressure equations for unsaturated soils were extended to account for the effect of temperature. For this purpose, the temperature-dependent suction stress-based effective stress is incorporated into 
formulations for calculating active and passive earth pressure profiles in unsaturated soils subject to elevated temperatures. The proposed suction stress framework is obtained from the extended SWRC model originally developed by Brooks and Corey, Darcy's flow principle, and Gardner's hydraulic conductivity function. The final formulation is simplified for hydrostatic condition (i.e., no flow conditions). The SWRC model considers the thermal effects on the surface tension of water, enthalpy of immersion and the contact angle.

To illustrate the temperature dependency of active and passive earth pressures, a parametric study was conducted with clay, silt, and sand at temperatures of 25, 40, and 55 ${ }^{\circ} \mathrm{C}$ under hydrostatic conditions. The results were presented in the form of active, and passive earth pressure profiles. The results suggested that elevated temperatures can have a significant effect on suction stress and thereby lateral earth pressures. For elevated temperatures, the suction stress increases, the active pressure decreases, and passive pressure increases. However, the variation of earth pressure magnitudes depends on depth, soil type and range of matric suction. For all soils, the tension zone increases with an increase in temperature from ambient conditions. The proposed approach can also be extended to different steady-state flow conditions like infiltration and evaporation.

\section{Acknowledgements}

This material is based upon work supported by the National Science Foundation under Grant No. CMMI-1634748. Any opinions, findings, and conclusions or recommendations expressed in this material are those of the authors and do not necessarily reflect the views of the National Science Foundation.

\section{References}

1. D.G. Fredlund, H. Rahardjo, Soil mechanics for unsaturated soils, John Wiley \& Sons, Inc., New York (1993)

2. N. Lu, W.J. Likos, Unsaturated soil mechanics, John Wiley \& Sons, New York (2004)

3. F. Vahedifard, B.A. Leshchinsky, K. Mortezaei, N. $\mathrm{Lu}$, Active earth pressures for unsaturated retaining structures. J. Geotech. Geoenviron. Eng., 141, 11 (2015).

4. W. Liang, J. Zhao, Y. Li, C. Zhang, S. Wang, Unified solution of Coulomb's active earth pressure for unsaturated soils without crack. Appl. Mech. Mater., 755-761 (2012)

5. S. Shahrokhabadi, F. Vahedifard, E. Ghazanfari, M. Foroutan, Earth Pressure Profiles in Unsaturated Soils under Transient Flow. Engineering Geology, 260, 105218, (2019)

6. M.A. Stewart, J.S. McCartney, An Analytical Model for Predicting Lateral Face Deflections of Thermally
Active Mechanically Stabilized Earth Walls. In International Symposium on Design and Practice of Geosynthetic-Reinforced Soil Structures. HI Ling, G. Gottardi, D. Cazzuffi, J. Han, F. Tatsuoka, eds. DEStech Publications, 233-242, (2013)

7. M.A. Stewart, C.J. Coccia, J.S. McCartney, Issues in the implementation of sustainable heat exchange technologies in reinforced, unsaturated soil structures. In Geo-Congress 2014: Geo-characterization and Modeling for Sustainability, 4066-4075, (2014)

8. J.S. McCartney, A. Martins de Assis, T. Silva Ribeiro, R. Costa Dos Santos, Nonisothermal response of reinforcing geogrids in thermally-active geotechnical systems. Proceedings of GeoAmericas 2016, the 3rd PanAmerican Conference on Geosynthetics. Miami. Apr. 10-13. 1-10, (2016)

9. C.J. Coccia, R. Gupta, J. Morris, J.S. McCartney, Municipal solid waste landfills as geothermal heat sources. Renewable and sustainable energy reviews, 19, 463-474, (2013)

10. A.M. Kasozi, R.V. Siddharthan, R. Mahamud, Temperature Distribution in Mechanically Stabilized Earth Wall Soil Backfills for Design Under Elevated Temperature Conditions. Journal of Thermal Science and Engineering Applications, 7(2), (2015)

11. J.W. Hopmans, J.H. Dane, Temperature Dependence of Soil Hydraulic Properties 1. Soil Sci. Soc. Am. J., 50, 1, 4-9, (1986)

12. S.A. Grant, A. Salehzadeh, Calculation of temperature effects on wetting coefficients of porous solids and their capillary pressure functions. Water Resour. Res., 32, 2, 261-270, (1996)

13. F. Vahedifard, T.D. Cao, S.K. Thota, E. Ghazanfari, Nonisothermal Models for Soil-Water Retention Curve. J. Geotech. Geoenviron. Eng., 144, 9 (2018)

14. F. Vahedifard, T. D Cao, E. Ghazanfari, S.K. Thota, Closed-Form Models for Nonisothermal Effective Stress of Unsaturated Soils. J. Geotech. Geoenviron. Eng., 145, 9 (2019)

15. A.W. Bishop, The principle of effective stress. Tecnisk Ukeblad, 39, 859-863 (1959)

16. N. Lu, J.W. Godt, D.T. Wu, A closed-form equation for effective stress in unsaturated soil. Water Resources Research, 46, 5 (2010)

17. N. Lu, W.J. Likos, Suction stress characteristic curve for unsaturated soil. J. Geotech. Geoenviron. Eng., 132, 2, 131-142, (2006)

18. R.H. Brooks, A.T. Corey, Hydraulic properties of porous media. Colorado State University, Fort Collins, Colo. Hydrology Paper No. 3, (1964)

19. S.K. Thota, T.D. Cao, F. Vahedifard, E. Ghazanfari, Stability Analysis of an Unsaturated Silty Slope under Nonisothermal Conditions. Geo-Congress-2019, GSP 310, 844-852 (2019) 